\title{
ACTION OF CHORIONIC GONADOTROPHIN ON CELLULAR STRUCTURES IN HUMAN ENDOMETRIUM IN THE SECRETORY PHASE
}

\author{
MIGHELINE ANCLA, J. BELAISGH AND J. DE BRUX \\ Institut National de la Santé et de la Recherche Médicale, Maternité de l'Hôtel Dieu, \\ and Hôpital Boucicaut, 78 rue de la Convention, Paris
}

(Received 21st Fune 1968)

\begin{abstract}
Summary. The injection of human chorionic gonadotrophin (HCG) may provoke a marked hyperplasia of certain structures appearing in the endometrial glandular cells at the beginning of the secretory period in women. The determinant factor in this hyperplasia would seem to be the excessive hormonal secretion of the ovaries provoked by HCG, in particular, the relative hypersecretion of progesterone.

The structures studied show a clearly marked cyclic evolution; certain of them present particular regressive forms, which the authors describe and interpret. Finally, their metabolic role is discussed, especially with regard to the relationship between glycogen and certain enlarged mitochondria.
\end{abstract}

\section{INTRODUCTION}

The period around the 20th day of the normal menstrual cycle is a critical one after fertilization has taken place, since it is at this time that the blastocyst implants itself in the uterine cavity (Hertig, 1967; Nilsson, 1962; Patten, 1953; Young, 1961). Electron microscope studies have shown that characteristic cellular structures develop in the endometrium between the 15th and the 25th days, i.e. they appear shortly after ovulation and disappear before the end of the cycle. These structures are found only in the glandular cells, either in the nuclei in the form of corpuscles, or in the cytoplasm in the form of giant mitochondria surrounding dense patches of glycogen (Ancla \& Belaisch, 1964; Ancla, de Brux, Musset \& Bret, 1967; Clyman, 1963; Gompel, 1964; Nilsson, 1962; Terzakis, 1965).

It has also been found that these same structures may undergo important morphological modifications during treatment with human chorionic gonadotrophin ( $\mathbf{H C G}$ ). Our observations in a number of cases appeared characteristic enough to undertake a closer study in order to attempt a functional interpretation.

\section{METHODS}

The endometrial biopsies, performed with the Novak curette, were examined both by light and electron microscopy. In the latter case, the samples were 
fixed either in osmium tetroxide or in glutaraldehyde buffer phosphate at $\mathrm{pH} \mathrm{7.2} \mathrm{and} \mathrm{post-fixed} \mathrm{in} \mathrm{osmium} \mathrm{tetroxide} \mathrm{and} \mathrm{embedded} \mathrm{in} \mathrm{Epon.} \mathrm{The} \mathrm{slides}$ were impregnated with uranyl acetate and lead nitrate, and were examined with an RCA-EMU-3 microscope.

Two groups of cases were studied: (1) more than ten control cases, untreated, and (2) nine patients presenting with primary sterility, in whom clinical studies revealed no abnormalities. The patients of the second group, having previously been examined in the luteal phase by sex-hormone assays, were subjected to a hypophysial stimulation-inhibition test (Jayle, 1963a, b). As soon as the rise in basal body temperature indicated the beginning of the luteal phase, the patients received $3 \mathrm{mg}$ of dexamethasone orally every day for 6 days, and 5000 units of HCG on the 1st, 3rd and 5th days of this treatment. On the 6th day urinary pregnandiol $(\mathrm{Pg})$, pregnantriol $(\mathrm{Pgt})$, oestrogens $\left(\mathrm{O}_{3}, \mathrm{O}_{1}, \mathrm{O}_{2}\right)$ and the fraction androsterone plus etiocholanolone of the neutral 17-ketosteroids were estimated.

The endometrial biopsy was performed following the second injection, i.e. on the 3rd, 4th or 5th day of the treatment, in order not to hinder the eventual implantation of an ovum.

\section{RESULTS}

All the endometria used for this study were, histologically, in the early secretory phase. Under the light microscope, this period is normally characterized by the presence of vacuoles rich in glycogen located in the basal portion of the glandular cells and under the electron microscope, very large mitochondria are seen near or in contact with sizeable patches of glycogen, while rounded corpuscles of canalicular structure appear in the nuclei (P1. 1, Fig. 1). In all cases, the development of these structures coincides with the beginning of the luteal (post-ovulatory) phase and the commencement of corpus luteum function: this has been corroborated by study of hormonal assays, basal temperature charts, cervical secretions and sometimes by coelioscopy (Ancla \& Belaisch, 1964; Ancla et al., 1967; Clyman, 1963).

Of the treated women, two groups were distinguished:

(1) seven patients presenting a normal endometrium;

(2) two patients whose biopsies deviated considerably from the normal, and whose hormonal assays showed a corresponding imbalance.

\section{EXPLANATION OF PLATE 1}

Fig. 1. Normal endometrium in initial luteal phase; basal portion of a gland. The cytoplasm contains patches of glycogen $(\mathrm{g})$ in the form of a scattering of black granulations, and abnormally voluminous mitochondria $(\mathrm{m})$ in the midst of other smaller ones; however, the larger ones do not exceed $2 \mu$ in diameter. Note the regular disposition of their cristae. $\times 14,070$.

FIG. 2. After injection of HCG at the beginning of the luteal phase, endometrium showing many exceptionally voluminous nuclear bodies (double in this case). These structures have a well-developed canalicular structure and may or may not be blended in with the nucleolar material. $\times 19,470$.

FIG. 3. After injection of HCG at the beginning of the luteal phase, an endometrial biopsy showing marked hypertrophy of the mitochondria. The system of cristae has become denser and more complex. $\times 25,530$. 
PL.IIY:

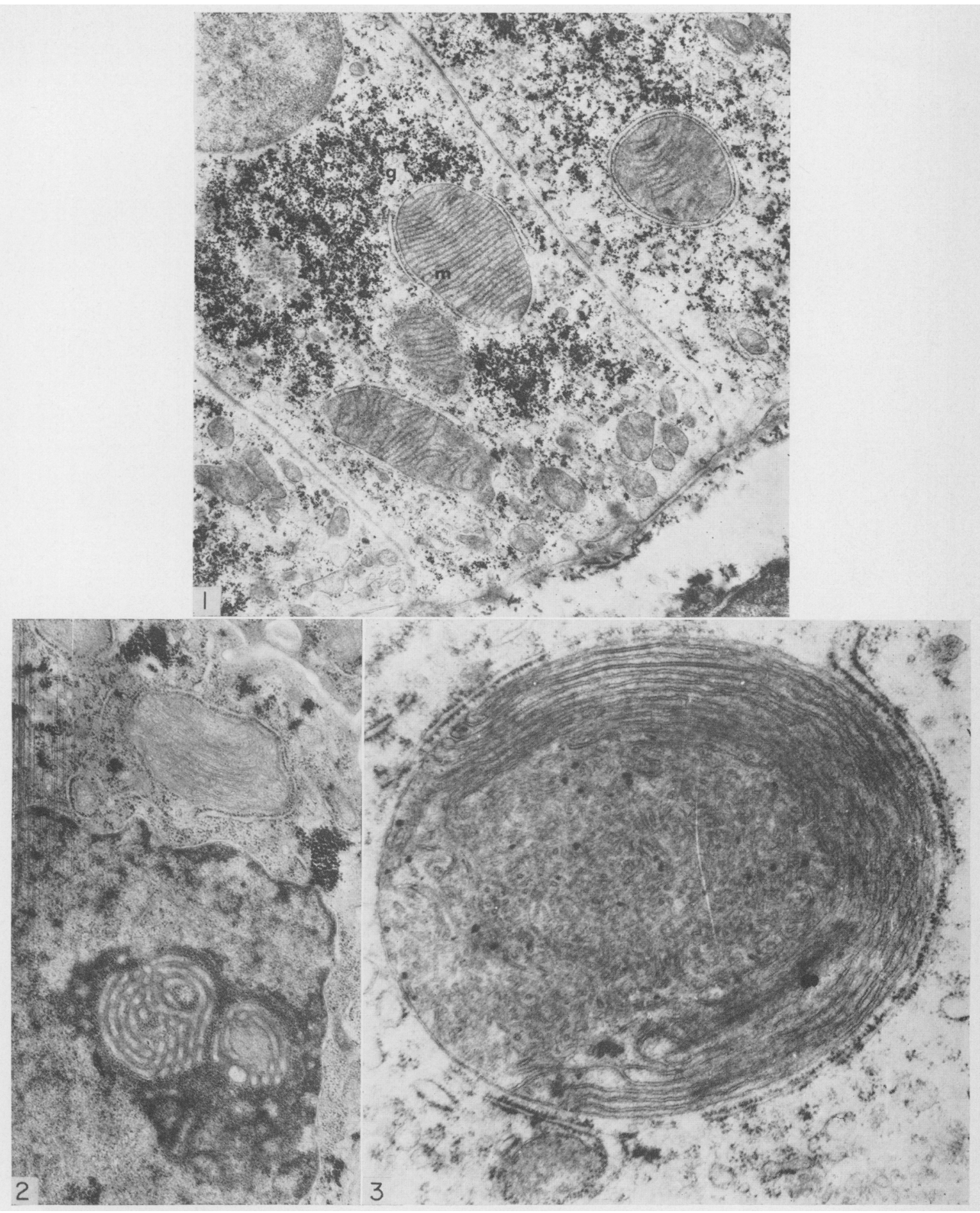

fracing p. 292. 
PISILL 2

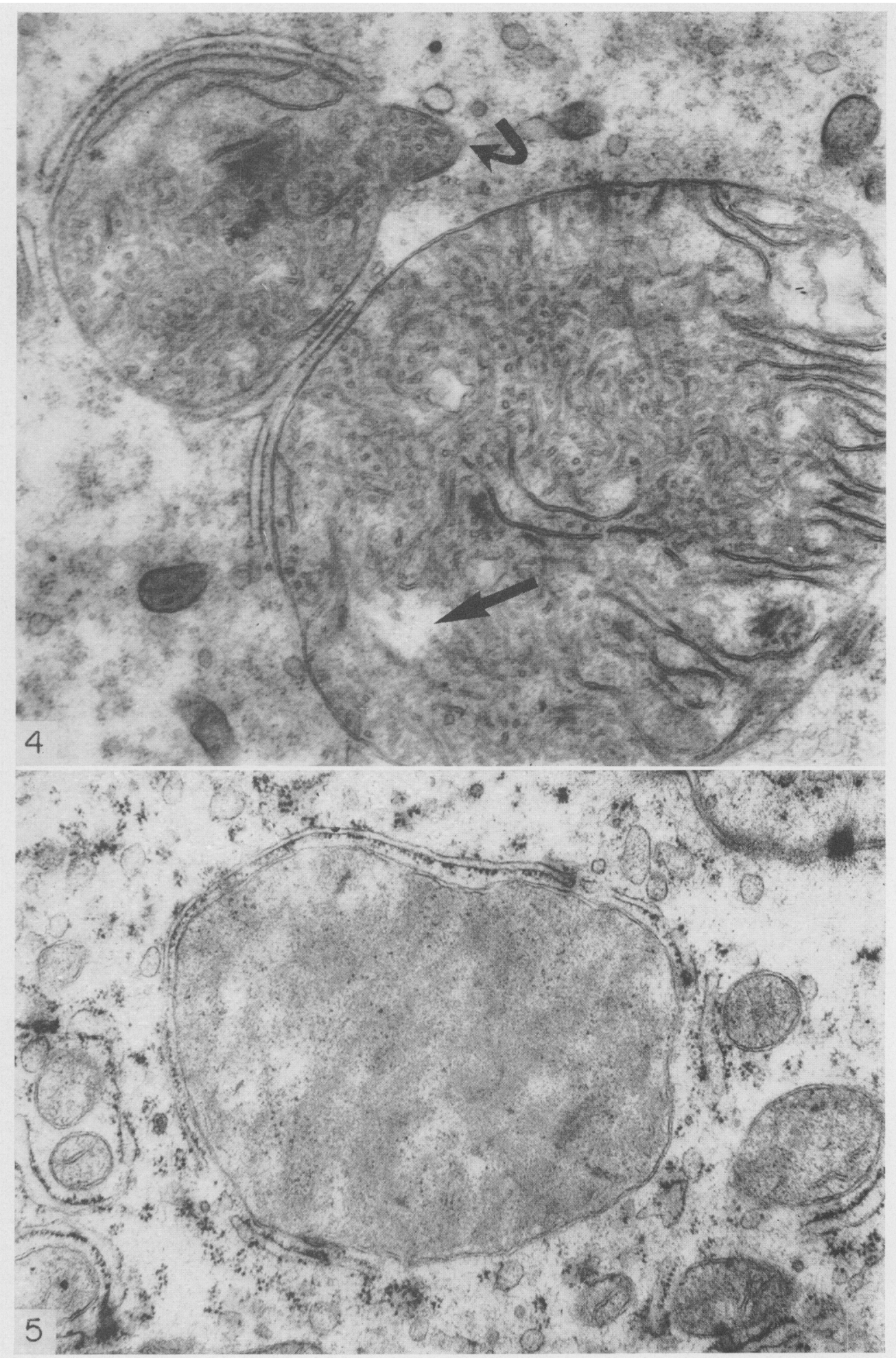


Under the light microscope these endometria showed no notable characteristic, but the electron-microscope showed marked hyperplasia of the structures mentioned above, in both of them. The nuclear bodies, the diameter of which normally varies from 0.5 to $1 \mu$, mostly exceeded $1 \mu$. They were also more complex, being formed by a greater number of tubules which, however, maintained a constant diameter. Although usually they occur singly, here there might be two or even three in a single nucleus (Pl. 1, Fig. 2), either blended with or distinct from the nucleolar material.

The 'normal' mitochondria of the post-ovulatory phase have an average diameter of 1.5 to $2.5 \mu$ (as compared with 0.5 and $1 \mu$ in the other phases of the cycle). This enlargement is apparently the expression of a true functional hyperplasia, since it is accompanied by an increase in the number of cristae; these latter are in regular parallel arrangement, disposed perpendicularly to the long axis of the mitochondrion (Pl. 1, Fig. 1).

After treatment with HGG, the volume of the mitochondria further increased, generally attaining $2.5 \mu$ and often exceeding $3 \mu$ (Pl. 1, Fig. 3; Pl. 2, Fig. 4). Here also there was hyperplasia of the system of cristae, which appeared more numerous within a given linear unit, at the point of their attachment to the internal mitochondrial membrane. It is notable that the cristae lost their regular parallel disposition, assuming multiple sinuosities of varying orientation, or sometimes grouping themselves in bundles of widely-undulating form. They also appeared narrower than in the normal state. The resulting images are very complex and tufted in appearance (Pl. 2, Fig. 4). The mitochondrial enlargement is sometimes accompanied by a tendency for budding to occur. There is a progressive evagination of the mitochondrial membrane which gradually becomes isolated, either by stretching out or by constriction (Pl. 2, Fig. 4), resulting in a daughter-mitochondrion equipped with a system of cristae which are relatively well-developed if not so numerous as those of the parent element.

Lastly, rounded or oval bodies, whose total diameter is of the same order as that of a mitochondrion, may also be observed, always at the base of the glandular cells. These bodies have the appearance of sacs bounded by a double or single membrane, whose contents are homogeneous and of medium density. One may often discern fragments of cristae, which may or may not be attached to the internal membrane, and which indicate their mitochondrial origin (P1. 2, Fig. 5).

Even allowing for the variations in the staining of glycogen by lead nitrate, it is rather more abundant than normally in the cells we have observed.

\section{DISGUSSION}

The findings described above will be discussed from the point of view of their hormonal dependence, their mode of development and their metabolic role.

EXPLANATION OF PLATE 2

FIG. 4. Very hyperplastic mitochondria during treatment with HCG. Numerous twisted cristae, forming a sort of skein. Presence of small clear areas (arrowed) devoid of cristae. $\times 23,480$.

Fig. 5. Voluminous residual mitochondrial sac, formed by a double membrane and containing an amorphous substance of medium density. $\times 30,160$. 
Action of $H C G$ : the rôle of progesterone

The aim of the stimulation-inhibition test is to transform the cyclic corpus luteum into a pseudopregnant one and by this means bring to light the secretory anomalies that would be produced if fertilization occurred. The average level of total oestrogens excreted on the 6th day of the test is $80 \mu \mathrm{g}$; that of pregnandiol, 6 to $7 \mathrm{mg}$, i.e. approximately twice the excretion observed in the middle of the normal luteal phase (Jayle, 1963a, b; Palmer, 1963).

It should be noted, however, that the effect of HCG on the oestrogen secretion is different from that on the secretion of pregnandiol. On this point, Geller (1967) has noted that the level of oestrogen increased with the duration of gonadotrophic stimulation, whereas that of the pregnandiol remained unchanged.

This was confirmed by the observation of Gemzell (1967), who administered 10,000 i.u. of HCG in one dose to patients who had been treated for 10 days with a standard dose of human hypophysial follicle-stimulating hormone without ovulatory results. The urine of these patients was gathered for a 9-hr period, in three samples taken every $3 \mathrm{hr}$. It was found that the three oestrogens reached a maximum in the second sample, but that the secretion of pregnandiol was not modified. Urine tested in the same manner in the luteal phase revealed a similar increase in oestrogens at the same moment, with no change in pregnandiol.

In our series of patients, a certain number presented evidence of deficiency of oestrogen production (frequent in cases of sterility). Only two of them had an endometrium abnormally rich in nuclear bodies and in over-developed mitochondria.

TABLE 1

\begin{tabular}{l|c|c|c|c}
\hline & $P g(m g)$ & $P g t(m g)$ & $O_{3}(\mu g)$ & $O_{1}-O_{2}(\mu g)$ \\
\hline Obs. 1 (Ro.) & 4 & 0.8 & 30 & 15 \\
Obs. 2 (Re.) & 8 & 1.8 & 20 & 15 \\
\hline
\end{tabular}

$\mathrm{Pg}=$ pregnandiol $; \mathrm{Pgt}=$ pregnantriol $; \mathrm{O}_{3}=$ oestriol

$\mathrm{O}_{1}=$ oestrone; $\mathrm{O}_{2}=$ oestradiol.

The first of these cases (Ro.- - see Table 1) had always presented a luteal deficiency characterized by low oestrogen levels, but showed no other anomaly which could explain her sterility. The latent oestrogenic deficiency of this patient had already been demonstrated, before the present study, by treatment with human menopausal gonadotrophin followed by hormonal assays.

The second case (Re.--see Table 1) also presented a definite deficiency of oestrogen production by the corpus luteum. In her case, the level of pregnandiol was normal.

This analysis leads to several hypotheses:

The hyperplasia of the cellular structures which characterizes these two observations may indicate only an endometrial anomaly having no relation with the hormonal state.

It may, on the contrary, reflect a hormonal imbalance. Our observations 
would seem to suggest an imbalance in which the secretion of progesterone-in the absence of an adequate oestrogenic stimulation to counterbalance itprovokes the mitochondrial enlargement and the hypertrophy of the nuclear bodies (Volk \& Scarpelli, 1966).

It is also possible that the endometrial biopsy was taken, by pure chance, at the moment of maximum gonadotrophic stimulation, and that the mitochondrial and nuclear modifications are a reflection of the sudden increase in oestrogenic secretion.

It is difficult to determine which of the latter two hypotheses is the more probable, especially in view of the uncertainty of the exact date of the endometrial sampling. In fact, as our endometrial biopsies were taken before the maximum effect of hypophysial stimulation was reached, the signs they show are probably related to the beginning of the gonadotrophic stimulation. However, it is not altogether certain that there is an absolute parallelism between the results of the hormonal tests and those of the histological study, as the latter preceded the hormonal assays by approximately 2 days.

\section{Morphological evolution of the cellular structures studied}

The cellular structures are remarkable because of their decidedly periodic and cyclic evolution (Ancla et al., 1967; Clyman, 1963), though little is known about the mechanism of this evolution. While glycogen is generally considered to be excreted into the lumen of the glandular tubules at the end of the menstrual cycle (Bontke, 1960; Boutselis, de Neef, Ullery \& George, 1963; Hagerman \& Villee, 1953; Mackay, Hertig, Bardawil \& Velardo, 1956; Stuermer \& Stein, 1952; Telfer \& Hisaw, 1957), in histological preparations it is found only in small quantities, mixed with a high proportion of glycoprotein. This would seem to indicate, either that it is secreted progressively, or that it is partially metabolized during the process. The nuclear bodies seem to disappear suddenly, as we were unable to observe regressive forms with any convincing precision.

We believe that the 'mitochondrial sacs', nearly or altogether devoid of cristae but filled with an amorphous homogeneous substance (PI. 2, Fig. 5), mentioned above, may represent a regressive form of the mitochondria, associated with a disintegration of the lipoprotein structure of the cristae and loss of the enzymatic activity (Gansler \& Rouiller, 1956). These sacs are found in the control patients as well as in the treated women, although they are perhaps more frequent in the latter. This disintegration would result in the formation of a residual sac. In the subsequent stage, the peripheral membrane presumably ruptures, allowing the contents of the sac to become incorporated with the rest of the cytoplasm. It should be noted that these mitochondrial sacs in no way resemble the disintegration bodies observed in certain processes of cellular lysis, particularly in the endometrium during the phase preceding menstrual desquamation (Ancla et al., 1967).

\section{Metabolic significance}

The evidence seems to show that the nuclear bodies represent a particular moment of nucleolar evolution (Ancla \& Belaisch, 1964; Clyman, 1963; Terzakis, 1965). It is possible that they follow a continuous cycle, traversing 
from the cytoplasm to the nucleoplasm, across the nuclear membrane which contributes to their special structure. Nevertheless, it seems very improbable that they have any relationship with the other structures considered, unless it be that of dependence on a common stimulus.

The question of glycogen and the mitochondria is more difficult, because of their spatial proximity. Nevertheless, certain authors have discarded the idea of an interdependence between them, basing their rejection on a study of the mink. Giant mitochondria, very similar to those observed in women, develop in this animal during the period of delayed implantation, and disappear at the moment of ovular nidation (fixation). Their presence does not seem to coincide with a notable cellular glycogen content (Enders, Enders \& Schlafke, 1963; Gompel, 1964).

It must be noted that these mitochondria appear in women, as in the mink, during the very limited period in which the ovum is found (or should normally be found in women) within the uterine cavity, not yet really fixed and having no means of autonomic nutrition. Considered from this point of view, there are two possible interpretations (Laborit, 1965): (1) that the mitochondria are necessary for the utilization of glycogen after its glycolytic transformation into pyruvate and acetyl-CoA (it is known that the mitochondria dehydrogenize their substrates, coupling the phosphorylations and the oxidations (Green \& Perdue, 1966; Laborit, 1965; Parsons, Williams \& Chance, 1966; Stoeckenius, 1966). Thus, the end-result of the hyperplasia and of the growth of the cristae would be a considerable synthesis of ATP, but it is not clear in what manner the ATP could be used by the ovum, nor for what reason; or (2) that the mitochondria are involved in neoglucogenesis and the synthesis of glycogen, the latter being necessary to 'feed' the glycolysis. (In support of this hypothesis, we know that the processes of rapidly-growing cells are essentially glycolytic.)

However, it cannot be assumed that these over-developed mitochondria behave normally. It may even be supposed that, because of their hypertrophy, their enzymatic equipment is atypical, adapted to the cellular metabolism peculiar to this moment; and it might be argued that it is the increased demands on certain types of enzymatic activity which result in hyperplasia of the corresponding cellular structures. In the case of the endometrium, the chainreactions called forth by the hormonal excess seem to be related to the presence of the mitochondrial cristae and, to a certain extent, to that of the membranes of the intranuclear bodies.

\section{ACKNOWLEDGMENTS}

We wish to thank Dr H. Laborit for the suggestions he kindly offered us, and Professor J. Lenegre for the use of his electron microscope.

\section{REFERENCES}

ANCLA, M. \& BeLAISCH, J. (1964) Action de la norethistérone sur certains corpuscles intranucléaires présents dans l'épithélium glandulaire de l'endomètre humain. Revue fr. Etud. clin. biol. 9, 490.

ANCLA, M., DE BRUX, J., Musset, R. \& BRET, J. (1967) Etude au microscope électronique de l'endomètre humain dans différentes conditions d'équilibre hormonal. Path. Biol., Paris, 15, 136. 
Bontre, E. (1960) Histochimie de l'endomètre prémenstruel et gravide. In: Les Fonctions de Nidation utérine et leurs Troubles. Colloque Soc. Nat. et Stér. Féc. Eds. J. Ferin and M. Gaudefroy. Masson, Paris.

Boutselis, J. G., de Neef, J. C., Ullery, J. C. \& GeorGe, O. T. (1963) Histochemical and cytologic observations in the normal human endometrium. I. Histochemical observations in the normal human endometrium. Obstet. Gynec., N.Y. 21, 423.

Clyman, M. J. (1963) A new structure observed in the nucleolus of the human endometrial epithelial cell. Am. 7. Obstet. Gynec. 86, 430.

Enders, A. C., Enders, R. K. \& Schlafke, S. (1963) An electron microscope study of the gland cells of the mink endometrium. F. Cell Biol. 18, 405.

Gansler, H. \& Rounller, C. (1956) Modifications physiologiques et pathologiques du chondriome. Etude au microscope électronique. Schweiz. Z. allg. Path. Bakt. 19, 217.

Geller, S. (1967) Excrétion des stéroides urinaires après transformation pseudogestative du corps jaune. In: Fonctions Endocriniennes de l'Ovaire. Gauthier-Villars, Paris.

Gemzels, G. A. (1967) Exploration dynamique des fonctions endocriniennes des ovaires. In: Fonctions Endocriniennes de l'Ovaire. Gauthier-Villars, Paris.

Green, D. E. \& Perdue, J. F. (1966) Correlation of mitochondrial structure and function. Ann. N.Y. Acad. Sci. 137, 667.

Gompel, C. (1964) Structure fine des mitochondries de la cellule glandulaire endométriale humaine au cours du cycle menstruel. 7. Microscopie, 3, 427.

Hagerman, D. D. \& VilleE, C. A. (1953) Effects of the menstrual cycle on the metabolism of the human endometrium. Endocrinology, 53,667.

Hertig, A. T. (1967) Human trophoblast: normal and abnormal. Am. F. clin. Path. 47, 249.

JAYLE, M. F. (1963a) Analyse des stéroides hormonaux, Vol. 3. Masson, Paris.

JAYLE, M. F. (1963b) Exploration dynamique de la fonction lutéale, VII ${ }^{\circ}$ Réunion des endocrinologues de langue française insuffisances lutéal et para-thyroid. Ed. A. Soulayrac. Masson, Paris.

LABORIt, H. (1965) Les régulations métaboliques. Masson, Paris.

Mackay, D. G., Hertig, A. T., Bardawil, W. A. \& Velardo, J. T. (1956) Histochemical observations on the endometrium I. Normal endometrium. Obstet. Gynec., N.Y. 8, 22.

Nirsson, O. (1962) Electron microscopy of the glandular epithelium in the human uterus. I. Follicular phase. II. Early and late luteal phase. F. Ultrastruct. Res. 6, 413, 422.

Palmer, R. (1963) Les explorations fonctionnelles gynécologiques. Masson, Paris.

Parsons, D. F., Williams, G. R. \& Chance, B. (1966) Characteristics of isolated and purified preparations of the outer and inner membranes of mitochondria. Ann. N.Y. Acad. Sci. 137, 643.

Patten, B. M. (1953) Human embryology. McGraw-Hill, New York.

StOeckenius, W. (1966) Morphological observations on mitochondria and related structures. Ann. N.Y. Acad. Sci. 137, 641 .

Stuermer, V. M. \& Stein, R. J. (1952) Cytodynamic properties of the human endometrium. V. Metabolism and the enzymatic activity of the human endometrium during the menstrual cycle. Am. 7. Obstet. Gynec. 63, 359.

TELfER, M. A. \& HISAw, F. L. (1957) Biochemical responses of the rabbit endometrium and myometrium to oestradiol and progesterone. Acta endocr., Copenh. 25, 390.

Terzakis, J. A. (1965) The nucleolar channel system of human endometrium. F. Cell Biol. 27, 293.

Volk, T. L. \& Scarpell, D. G. (1966) Mitochondrial gigantism in the adrenal cortex following hypophysectomy. Lab. Invest. 15, 707.

Younc, W. C. (1961) Sex and internal secretions. Baillière, Tindall and Cox, London. 